\title{
Final Report: High-Resolution Modeling to Assess Tropical Cyclone Activity in Future Climate Regimes
}

US Department of Energy: DOE-Grant DE-FG02-07ER64448

Principal Investigators: Gary Lackmann, Anantha Aiyyer, Lian Xie, Fred Semazzi

Renewal: Lackmann

North Carolina State University

\section{Condensed Summary:}

Work supported by this project included (i) assessment of general circulation model output (Aiyyer and Talgo), (ii) novel methods for downscaling (Xie, Liu, Peng, and Semazzi), and (iii) the impact of climate change on tropical cyclone intensity and frequency (Lackmann, Hill, and Gentry/Mallard). The project supported 1 MS student and 2 PhD students; all of these students are now employed professionally in closely related fields of study. A total of 9 full-length, peerreviewed journal articles were supported by this project, along with at least 15 conference and invited workshop/symposium presentations.

Central to the problem of future tropical cyclone activity is the ability of GCMs to consistently represent vertical wind shear in the main tropical cyclone development regions. To this end, Dr. Anantha Aiyyer, working with graduate student Kevin Talgo, undertook a detailed analysis of the $20^{\text {th }}$ century output from the IPCC AR4 GCMs to assess the consistency between observational analyses and the models. First, it was found that projected increases in Atlantic basin shear are much less robust when statistical significance of the shear increase is taken into account, contrary to some previous publications. Analysis of the ENSO-shear and Sahel-shear relations for the Atlantic basin reveal that some of the models are in reasonable agreement with the NCAR/NCEP reanalysis, but many others are not. GCM representation of the African monsoon system also accounts for substantial variability in projections of Atlantic shear. These results are presented in Talgo (2009), and a journal publication based on this thesis will be forthcoming. 
Other objectives include the development and application of the scale-selective data assimilation (SSDA) approach (Peng et al. 2009; Xie et al. 2010), and the further development of a 3-way coupled wave-ocean-atmosphere model (Liu et al. 2011). By assimilating only large-scale information on a high-resolution model nest, improved downscaling performance is obtained; this result has important implications for seasonal-scale prediction of tropical cyclones as well as for climate-related downscaling efforts.

Another component of the supported work assessed the impact of climate change on the frequency and intensity of tropical cyclones via high-resolution numerical model experiments. The Weather Research and Forecasting (WRF) model is utilized in a series of idealized simulations designed to isolate the thermodynamic impact of climate change on the structure and intensity of tropical cyclones (TC). By running these experiments at very high resolution (2- and 6-km grid length), we were able to capture the full circulation and intensity of the numerical TC without resorting to convective parameterization. Idealized tropical cyclones are allowed to attain quasi-steady intensity in an idealized environment based on current tropical conditions. These simulations are compared to those that account for the thermodynamic changes derived from an ensemble of widely used general circulation model (GCM) projections (a set of 13 IPCC AR4 simulations) for three emission scenarios. Structural TC changes arising from climate change, along with an understanding of their physical cause, are derived from TC simulations at 6- and 2-km grid spacing. Additionally, through the use of an ensemble of GCM projections, in addition to an ensemble of WRF simulations, the sources of uncertainty in the range of intensity changes are quantified.

Future storms exhibit a 9-14\% increase in intensity for future conditions corresponding to the period from 2090-2099 (Hill and Lackmann 2010). The depth of the cyclonic circulation increases, consistent with increases in the freezing level and tropopause height. Inner core precipitation increases between 10 and $30 \%$ in the future storms, with large sensitivity to emission scenario. The heavier precipitation is dynamically linked to the intensity increase through enhanced diabatic potential vorticity production in the future storms. It is shown that enhanced upper-tropospheric warming in GCM projections is a critical mitigating effect on TC intensity, but it is also demonstrated that the extent of this warming is a major source of uncertainty, exhibiting strong variability in the GCM simulations. A 78-member ensemble of 6- 
$\mathrm{km}$ WRF simulations, drawing from a range of IPCC SRES scenarios and GCM data available through the PCMDI project, has enabled us to quantify uncertainties in future TC intensity. One important aspect of the uncertainty in the future projections is the very large standard deviation in GCM-projected changes in the tropical upper-tropospheric temperature profile (Hill and Lackmann 2010). A second set of WRF simulations featuring 2-km grid spacing were used to diagnose the structure of simulated current and future TCs, allowing examination of differences in the size, intensity, and precipitation between present and future.

Several previous studies have found a decrease in the frequency of tropical cyclones with climate warming (e.g., see review of Knutson et al. 2010). Several different physical mechanisms have been proposed to explain this finding, and the dissertation goal of Megan Gentry (now Mallard) was to understand which of the proposed mechanisms is responsible. Using a series of very-high resolution Atlantic Basin simulations (with 6-km grid length over the entire North Atlantic development region), current and future simulations were conducted with the same synoptic patterns, but with and without climate warming. The results were consistent with previous work in that the frequency of future tropical cyclones diminished. Our experimental design allowed a clear look at the cause: The frequency reduction is a thermodynamic effect (Mallard et al. 2013a, Mallard et al. 2013b).

An additional result of this project was a novel finding on the environmental control of tropical cyclone size (Hill and Lackmann 2009, Mon. Wea. Rev.); this article was featured as a "Paper of Note" in the Bulletin of the AMS. As of 6 June 2013, Google Scholar lists 50 citations of this paper, indicating that it was received with interest in the tropical cyclone community.

The project allowed development of infrastructure to study a set of other problems, including examination of extreme precipitation under climate warming. Another study, jointly supported by this DOE project and NSF award, analyzed the change in character of a flooding event that took place in the south-central US in early May 2010 that could take place under climate warming (Lackmann, 2013).

\section{Personnel:}

Kevin Talgo graduated with his M.S. in 2009, supported by this DOE grant, and is now employed at the UNC - Institute for the Environment. 
Kevin Hill graduated in the summer of 2010 with his Ph.D. having been supported by this DOE grant. Kevin is now employed by AIR Worldwide in Boston, MA.

Megan Gentry (now Mallard) graduated in the fall of 2011, having been supported by this DOE grant. Megan is now a postdoctoral scholar supported by the ORISE program, working at the US EPA.

\section{Peer-Reviewed Publications supported by this project:}

Hill, K. A., and G. M. Lackmann, 2009: Influence of environmental humidity on tropical cyclone size. Mon. Wea. Rev. 137, 3294-3315.

Gentry M. S., and G. M. Lackmann, 2010: Sensitivity of simulated tropical cyclone structure and intensity to horizontal resolution. Mon. Wea. Rev. 138, 688-704.

Hill, K. A., and G. M. Lackmann, 2011: The impact of future climate change on tropical cyclone intensity and structure: A downscaling approach. J. Climate, 24, 4644-4661.

Lackmann, G. M., 2013: The south-central US flood of May 2010, present and future. $J$. Climate, in press.

Liu, B., H. Liu, L. Xie, C. Guan, and D. Zhao, 2011: A coupled atmosphere-wave-ocean modeling system: Simulation of the intensity of an idealized tropical cyclone. Mon. Wea. Rev.,139, 132-152.

Mallard, M. S., G. M. Lackmann, K. A. Hill, and A. Aiyyer, 2013a: Atlantic hurricanes and climate change. Part I: Seasonal-scale simulations using WRF. J. Climate, in press.

Mallard, M. S., G. M. Lackmann, and A. Aiyyer, 2013b: Atlantic hurricanes and climate change. Part II: Seasonal-scale simulations using WRF. J. Climate, in press.

Peng, S., L. Xie, B. Liu, and F. Semazzi, 2009: Application of scale-selective data assimilation to regional climate modeling and prediction. Mon. Wea. Rev., 138, 1307-1318.

Xie, L., B. Liu, and S. Peng, 2010: Application of scale-selective data assimilation to tropical cyclone track simulation. J. Geophys. Res., DOI: 10.1029/2009JD013471. 


\section{Theses and Dissertations:}

Talgo, K., 2009: Tropical Atlantic vertical wind shear variability in a future climate. Master of Science Thesis, North Carolina State University, available online from http://www.lib.ncsu.edu/theses/available/etd-10302009-105719/.

Hill, K., 2010: Climate and tropical cyclones. Doctor of Philosophy Dissertation, available online from http://www.lib.ncsu.edu/resolver/1840.16/6553.

Gentry, M. S., Hill, 2011: Atlantic hurricanes and climate change. Doctor of Philosophy Dissertation, available online from URI: http://www.lib.ncsu.edu/resolver/1840.16/7184.

\section{Conference extended abstracts:}

Gentry, M. S., and G. M. Lackmann, 2008: Sensitivity of numerically simulated tropical cyclone structure and intensity to changes in horizontal resolution. $28^{\text {th }}$ Conference on Hurricanes and Tropical Meteorology, poster P1F.2

Gentry, M. S., and G. M. Lackmann, 2008: High-resolution WRF simulations of an Atlantic hurricane season. $28^{\text {th }}$ Conference on Hurricanes and Tropical Meteorology, presentation 6B.5

Hill, K. A., and G. M. Lackmann, 2008: Model simulated changes in maximum TC intensity due to global warming. 28th Conference on Hurricanes and Tropical Meteorology, presentation 7B.2

Lackmann, G. M., and K. A. Hill, 2008: Environmental Influence on Tropical Cyclone Size. $28^{\text {th }}$ Conference on Hurricanes and Tropical Meteorology, presentation 13C.2

Talgo, K. and A. Aiyyer, 2008: Analysis of environmental factors associated with tropical cyclone activity in a future climate. $28^{\text {th }}$ Conference on Hurricanes and Tropical Meteorology.

Lackmann, G. M., 2009: High-Resolution Modeling to Assess Tropical Cyclone Activity in Future Climate Regimes. DOE CCPP Science Meeting, Bethesda, MD April 2009. 
Lackmann, G. M. 2010: The structure of cyclonic systems in changing thermodynamic environments. 24 September 2010, 50 $0^{\text {th }}$ Anniversary Scientific Program, Department of Atmospheric and Oceanic Sciences, McGill University, Montreal, Quebec, Canada.

Lackmann, G. M., 2010: Environmental influences on tropical cyclones. 4 October 2010, 50 ${ }^{\text {th }}$ Anniversary Celebration of Atmospheric Sciences at the University at Albany, Albany, New York.

Hill, K. A., and G. M. Lackmann, 2010: The impact of future climate change on tropical cyclone intensity and structure: A downscaling study. AMS $29^{\text {th }}$ Conference on Tropical Meteorology and Hurricanes, Tucson, AZ, May 2010.

Gentry, M. S., and G. M. Lackmann, 2010: Atlantic hurricanes and climate change: Projection of a peak month in a future record hurricane season. AMS $29^{\text {th }}$ Conference on Tropical Meteorology and Hurricanes, Tucson, AZ, May 2010.

Lackmann, G. M., 2011: A Cyclonic Low-Level Jet in a Warmer Climate. $15^{\text {th }}$ Cyclone Workshop, Monterey, CA, 28 March 2011.

Lackmann, G. M., 2012: The Cyclonic Low-Level Jet in a Warmer Climate (7B.3), AMS $92^{\text {nd }}$ Annual Meeting, $24^{\text {th }}$ Conference on Climate Variability and Change, New Orleans, Louisiana, 25 January 2012.

Lackmann, G. M., and M. S. Gentry, 2012: Fewer future hurricanes: Why? (12B.2). AMS $92^{\text {nd }}$ Annual Meeting, $24^{\text {th }}$ Conference on Climate Variability and Change, New Orleans, Louisiana, 26 January 2012.

Lackmann, G. M., 2012: Cyclones and climate change. Southeastern Coastal and Atmospheric Processes Symposium (SeCAPS), University of South Alabama. Keynote presentation, 24 March 2012, Mobile, AL.

Lackmann, G. M., 2012: Tropical cyclones, low-level jets, and thermodynamic climate change. Canadian Meteorological and Oceanographic Society (CMOS) 2012 Congress joint with AMS Weather Analysis and Forecasting/Numerical Weather Prediction, 30 May 2012, Montreal, Quebec, Canada. 